\title{
Evaluation of Operating Conditions of a Sleeve Filter for Coal Emission Control
}

\author{
Guilherme Rufatto Schmidt ${ }^{2}$ and Luciano Peske Ceron ${ }^{1,2}$ \\ 1. School Polytechnic, Pontifical Catholic University of Rio Grande do Sul, Porto Alegre, Rio Grande do Sul 90619-900, Brazil \\ 2. Chemical Engineering Course, PUCRS, Porto Alegre, Rio Grande do Sul 90619-900, Brazil
}

\begin{abstract}
The emission of fine particulates from the burning of coal can pose a number of problems for human health and the environment. The bag filter is an equipment capable of preventing these particles from reaching the atmosphere. The present work evaluated and proposed improvements based on information received from a process of a company producing vegetable bran and oils, which acts with high emission of particulates. The filter sleeves used were fiberglass fabric with expanded polytetrafluoroethylene membrane. Physical, mechanical and granulometric laboratory analyzes were performed, as well as scanning electron microscopy and dispersive energy spectroscopy for the characterization of the tissue and particulate matter. Based on the results, a new specification of stainless steel cage was proposed for the filter in order to improve the efficiency of retention, as well as to increase the useful life of the filter elements.
\end{abstract}

Keywords: Bag filter, fiberglass, polytetrafluoroethylene.

\section{Introduction}

The introduction of the paper should explain the nature of the problem, previous work, purpose and the contribution of the paper. The contents of each section may be provided to understand easily about the paper. The particulate matter is a heterogeneous and complex mixture composed of particles capable of transporting a great variety of chemical compounds harmful to human health [1]. Long-term exposure to high concentrations of particulate matter may increase the risk of lung cancer, chronic obstructive respiratory diseases, and arteriosclerosis, while short-term exposure may cause other respiratory diseases, including bronchitis and asthma [2].

The current National Council of Environment Resolution No. 436 of December 22, 2011, Annex XIII establishes the emission limit for particulate matter in a coal kiln to be $50 \mathrm{mg} / \mathrm{Nm}^{3}$ and, in order to maintain air quality within these standards, the sleeve

Corresponding author: Luciano Peske Ceron, Ph.D., main research field: environmental engineering. filters are the most suitable equipment for this operation [3]. The sleeves whose purpose is to remove solid particles of gases produced in the industries before they reach the atmosphere, may be a fabric or a non-woven fabric [4]. The nonwoven is produced without an orderly and homogeneous interweaving of the yarns, but with a random distribution of fibers, different from a fabric, which has its array of yarns formed by an angle close to $90^{\circ}$ [5].

The objective of this work is to evaluate the conditions of operation of filter elements in filter of sleeves in the industry of bran and vegetal oils in function of information received from the process. The equipment currently operates with high emission of fine particulates, generated by coal burning in a boiler furnace. The sleeves used are fiberglass fabric with expanded polytetrafluoroethylene membrane, and have 12 months of use. According to the manufacturer, the sleeves must be effective for at least 24 months. Thus, scanning electron microscopy, dispersive energy spectroscopy, physical, mechanical and granulometric laboratory analyzes were performed to 
characterize the process. In conclusion, suggestions were made to improve the process.

Electrostatic precipitators and manhole filters are the most commonly used equipment for the separation of solid particles from process gas streams [6]. However, only mango filters are able to retain very fine particles, such as those generated in coal burning, and have excellent separation efficiency, with values above $99.99 \%$ [7]. In the manhole filter, the contaminated gas enters through a tubing on the side of the equipment and the contact with the filtering medium occurs, causing the soils to be captured and deposited on the surface of the material, forming a layer of dust called filter cake. Finally, clean air exits the upper end of the filter and can be released into the atmosphere [8]. Fig. 1 represents the flow of contaminated air in red and the clean stream being released to the external environment in blue.

The fiberglass is one of the best materials among the main available in the market, because it resists to the high operating temperatures, has excellent resistance to the traction, in addition to being very resistant chemically. However, it is brittle to abrasion, notwithstanding high Ar-Cloth ratios (RAP); therefore, it is indicated for values up to 0.90 $\mathrm{m}^{3} / \mathrm{m}^{2} \cdot \min [9]$.

A thin layer, said expanded PTFE membrane, is deposited by the lamination process in fabrics, for example in glass fiber [10]. The bonding of the two materials makes the fabric resist very severe chemical attacks of concentrated acids and bases, obtaining high resistance to hydrolysis and oxidation [11]. In addition, PTFE is one of the most commonly used membranes for surface filtration as it provides highly efficient filtration that effectively suspends dust and moisture, especially for small particle size [12].

The sleeve filter requires cages to support each filter sleeve attached to the sleeve filter, as shown in Fig. 2. The most characteristic example of corrosion in cages is the oxidation of iron, better known as rust in popular language. Iron is easily oxidized when put in contact with air and moisture. In addition to the oxygen present in the air and moisture, other factors also accelerate the formation of rust, such as sulfur dioxide $\left(\mathrm{SO}_{2}\right)$ and other acidic compounds, although they are not capable of provoking it alone [13].

In practice, a minimum operating temperature of $25{ }^{\circ} \mathrm{C}$ above the highest acid dew point calculated, or sufficient to maintain the temperature at the outlet of the equipment at $15{ }^{\circ} \mathrm{C}$ above this point, is within the operating limits of the filter sleeve. The ideal is a continuous process (without stops) at a temperature above $145{ }^{\circ} \mathrm{C}$, avoiding the passage through the zone of acid condensation, generally between $115{ }^{\circ} \mathrm{C}$ and $140{ }^{\circ} \mathrm{C}$. This condition alleviates accelerated oxidation

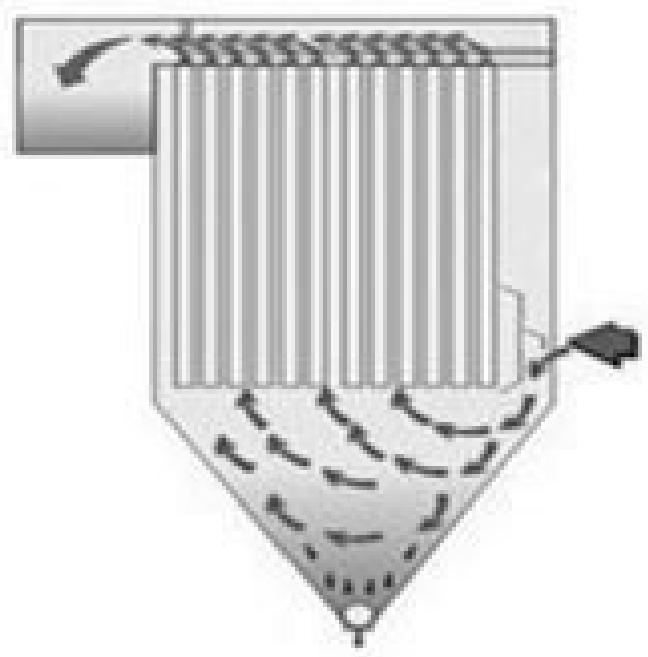

Fig. 1 Air flow in the sleeve filter.

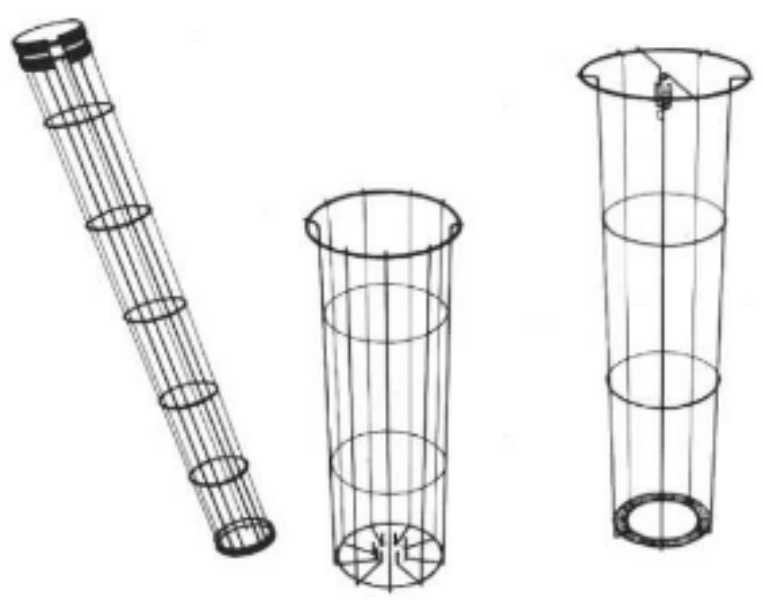

Fig. 2 Cages to support the sleeves. 
in galvanized cages, as well as prevents an early saturation of the filter element due to condensation and humidity [14].

Sleeves with PTFE membrane have excellent resistance to hydrolysis and acids, the cage can be compromised by oxidation and, with its rough surface, damage the filter material by contact abrasion. In general, the consequences of such oxidation to the filter elements are the occurrence of tears and holes, reducing the service life of the sleeves [15].

\section{Experimental Setup}

The methodology adopted was to evaluate the conditions of the current dirty filter elements, after 12 months of use, through laboratory analysis and to compare them with a new sleeve, standards and needs for application. The filter sleeves had tears and punctures in the application; therefore, there was a high emission of particulates beyond $50 \mathrm{mg} / \mathrm{Nm}^{3}$ allowed by the CONAMA 436 legislation. In this application, it is common for filter sleeves to last approximately 24 months with an average emission rate of $20 \mathrm{mg} / \mathrm{Nm}^{3}$, with use of $316 \mathrm{~L}$ stainless steel cages that are changed every 48 months. Due to economy, it was the first time they used galvanized cages, which are cheaper.

The analyzed filter elements were manufactured in Renner Têxtil, have a composition of $100 \%$ fiberglass fabric with PTFE membrane. The granulometric analysis of the particulates was performed according to the ABNT NBR NM 248 standard and was given at the Laboratory of Environmental Processes (LAPA), located at the Pontifical Catholic University of Rio Grande do Sul.SEM analysis was used to characterize both the clean filter material and also to identify the deposition of the particulates in the fibers of the dirty material. Dispersive energy spectroscopy, in turn, was used to evaluate the chemical characterization of the samples. The analyzes were carried out in a Philips scanning electron microscope, model XL 30, with acceleration voltage of $20 \mathrm{kV}$, at the Central Laboratory of Microscopy and Microanalysis of Pontifical Catholic University of Rio Grande do Sul. The air permeability was determined according to NBR 13706: 1996 in triplicate. The analysis used a Permeabilimetro Karl Schroder KG, model 6940 Weinheim, and considered dirty samples taken directly from the process, besides samples that underwent a cleaning simulation. The weight and thickness tests were performed, respectively, according to NBR 12984: 2009 and NBR 13371: 2005 standards.

The mechanical strength tests were performed by a Frank 81565 IV dynamometer with longitudinal and transverse force application, according to NBR 13041: 1993. The specimen was trapped between the claws as tightly as possible, and then underwent a load of 10 $\mathrm{kN}$ with a vertical clearance velocity of $100 \mathrm{~mm} / \mathrm{min}$ until its rupture. The samples used were dirty, removed directly from the process.

\section{Results}

\subsection{Calculation of RAP}

The mathematical determination of filtration rate (RAP) presented in Table 1 was performed by Eq. (1), where $\mathrm{Q}$ is the flow rate, $\mathrm{N}$ is the number of sleeves and $\mathrm{A}$ is the total filtering area of a sleeve [16].

$$
R A P=Q /(N . A)
$$

The calculated RAP is $0.80 \mathrm{~m}^{3} / \mathrm{m}^{2}$. $\mathrm{min}$; therefore, it is in accordance with Ceron recommendation (2009), under normal conditions for application, since the maximum value allowed is up to $0.90 \mathrm{~m}^{3} / \mathrm{m}^{2} \cdot \min$. In this sense, the filter design was well performed for the desired flow rate.

Table 1 Current filter setting.

\begin{tabular}{ll}
\hline Relations & Informations \\
\hline Flow rate $\left(\mathrm{m}^{3} / \mathrm{h}\right)$ & 97.000 \\
Number of Sleeves & 1,200 \\
Dimensions of Slleves $(\mathrm{mm})$ & $156 \times 3,440$ \\
Area per Sleeve $\left(\mathrm{m}^{2}\right)$ & 1,686 \\
Total Filtration Area $\left(\mathrm{m}^{2}\right)$ & 2.023 .2 \\
RAP $\left(\mathrm{m}^{3} / \mathrm{m}^{2} . \mathrm{min}\right)$ & 0.80 \\
\hline
\end{tabular}




\subsection{Visual inspection}

Fig. 3 shows the nozzle of the sample with abrasive process ruptured fiber in several parts and rust marks from the cage. On the outside, there was a great accumulation of dark particulate, abrasive process marks with holes and micro-holes, besides the agglutination and formation of small stones, which is characteristic of condensation and humidity in the filtration system.

In the inner part, Fig. 4, high dirt, rust marks, micro holes and completely ruptured fiberglass structure were observed. In addition, a more aggressive abrasive process was identified when compared to the other parts of the sleeve, as well as large deposition of sharp metals, probably resulting from the oxidation of the cage.

\subsection{Visual inspection}

Weight and permeability were also evaluated after beating cleaning simulation and, even so, kept their values far from ideal, indicating complete saturation. These results in Table 2 are due to the high deposition of particulate material that is favored both by the holes and tears, as well as by the humidity and condensation found in the process which, due to the high percentage

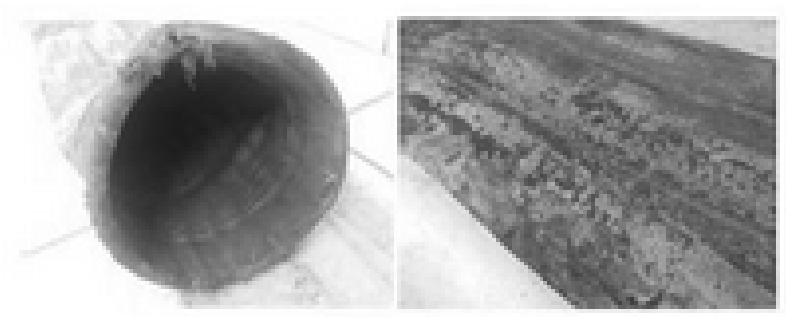

Fig. 3 Nozzle and outer side.
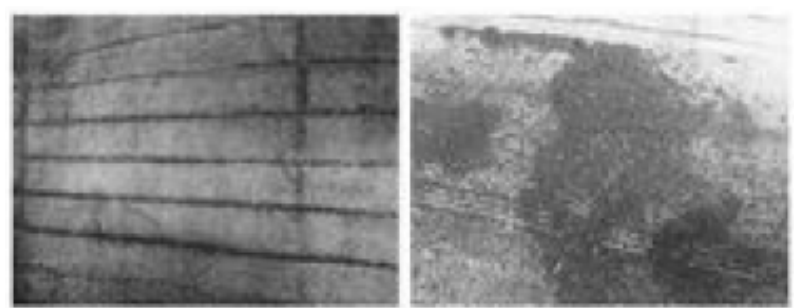

Fig. 4 Inside sleeve. of fine particulates, are favorable to surface saturation.

The results of the mechanical tests, presented in Table 3, also did not obtain the performance expected by the manufacturer. The top and bottom samples have low tensile and tensile strengths, which means that the material does not fully perform the expansion movement (internal cleaning by pulsating compressed air) and retraction (during the normal filtration process), that is, there is a need for material replacement, since a large loss of load is estimated in the process.

\subsection{Granolometric test}

Fig. 5 shows the granulometric distribution with the respective retained percentages of particulates in each sieve. It is possible to identify a large quantity of fine particulates, having the smallest sieve $(45 \mu \mathrm{m})$ and the pan with $39.86 \%$ of the total solids.

Table 2 Physical test results.

\begin{tabular}{lllll}
\hline Analyze & Condition & Top & Fund & Standard \\
\hline Gramage & Dirty & 925 & 1,072 & 750 \\
$\left(\mathrm{~g} / \mathrm{m}^{2}\right)$ & Clean & 885 & 981 & 750 \\
Air Permeability & Dirty & 8 & 5 & 40 \\
$\left(\mathrm{~L} /\right.$ min. $\left.^{2} \mathrm{dm}^{2}\right)$ & Clean & 10 & 7 & 40 \\
Thickness $(\mathrm{mm})$ & Dirty & 1.6 & 1.8 & 0.8 \\
\hline
\end{tabular}

Table 3 Results of mechanical tests.

\begin{tabular}{llcll}
\hline Analyze & Condition & Top & Fund & Standard \\
\hline Tensile Strength & Lenght & 950 & 710 & 4,300 \\
(N) & Cross & 550 & 470 & 2,000 \\
Stretching up to & Lenght & 3 & 2 & 10 \\
$\begin{array}{l}\text { rupture } \\
(\%)\end{array}$ & Cross & 4 & 3 & 10 \\
\hline
\end{tabular}

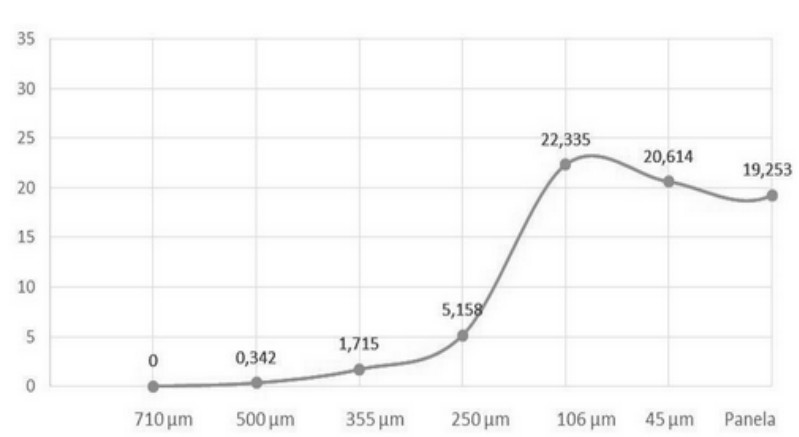

Fig. 5 Particle size distribution. 


\subsection{Scaning Electron Microscopy (SEM) and Dispersive Energy Spectroscopy (EDS)}

The glass fibers of the new filter cloth, never before used, are represented by Fig. 6. Electron microscopy showed an interlacing of the fibers at an angle close to $90^{\circ}$, with an average width of $833.4 \mu \mathrm{m}$.

The analysis of the dirty sample was made on the outside and inside of the sleeve, represented respectively in Fig. 7. The outside indicated complete saturation of the filter, without possibility of visualization of the fibers by excess of coal. The inner part, on the other hand, even with the material completely saturated, did not present such a quantity of particulate; however, this behavior was expected, since there is surface filtration for this material.

The dispersive energy spectroscopy of the inner part of the sample is represented by Fig. 8. All elements found were predicted, with the exception of gold $(\mathrm{Au})$, which comes from the preparation of the sample, not actually present in the process, and iron (Fe), which identifies the oxidation of the cage. As for the outside, there were no abnormalities.

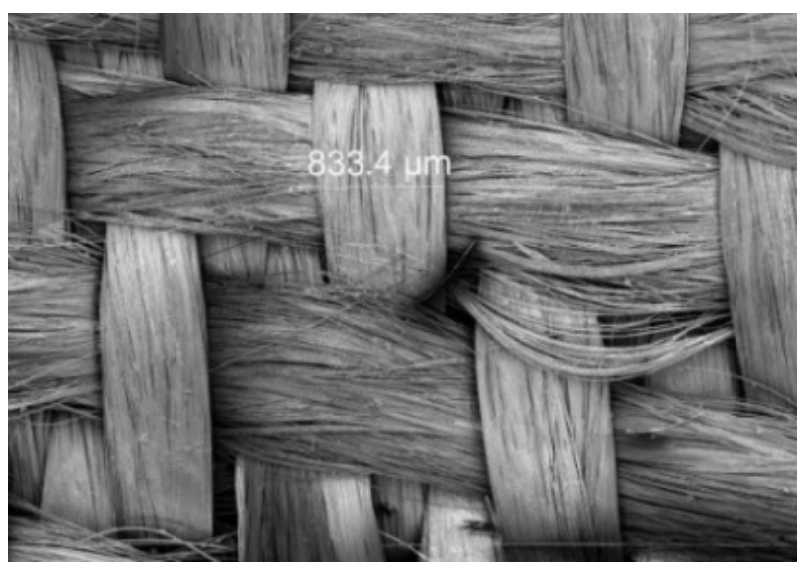

Fig. 6 SEM analysis of new filter cloth.
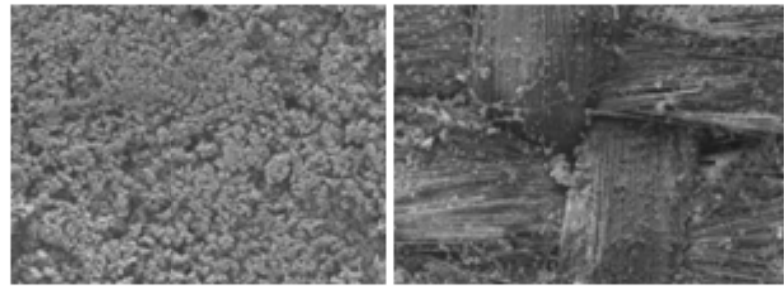

Fig. 7 SEM external and internal side.

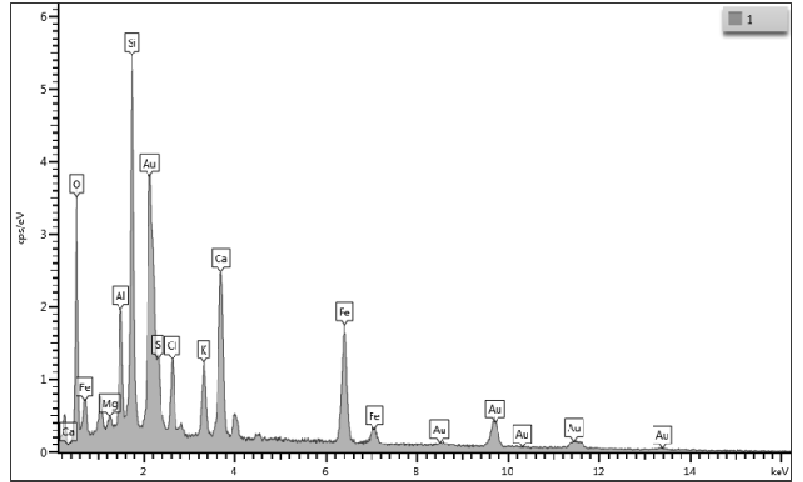

Fig. 8 EDS analysis of the internal part.

\section{Conclusion}

The present study arose from the need for environmental control required by the legislation in force in a company producing bran and vegetable oil, which emitted more volume of coal particles to the atmosphere than allowed. The results of the permeability test and scanning electron microscopy analysis showed that, at 12 months of use, there is complete saturation of the filter material, with no possibility of reusing it, which should be effective for at least 24 months. The oxidation of the galvanized cage is the main reason for the significant reduction in the useful life of the material, as well as the accumulation and agglutination of particulate material that obstructs the passage of gas.

The oxidation of the cage is confirmed by the presence of iron in the sleeve, confirmed by the dispersive energy spectroscopy, as well as visual marks present on the sleeves and the deposition of metallic material. PTFE membrane fiberglass is very resistant to various conditions, but is brittle to abrasion. Therefore, to improve the process conditions, it is recommended that the galvanized cage be replaced with a stainless steel that, although more expensive, will not oxidize in the presence of oxygen and moisture, nor under acidic conditions. In this way, the filter cloth will have an increase in its useful life, since it will not suffer abrasion, reason why the mechanical and physical tests are diverging of the expected standard. 
The clogging of the gas passage due to the accumulation and agglutination of particulate is due to the excessive humidity and acid condensation in which the process was, therefore, another improvement to be made is in the control of water condensation. It is recommended to maintain a minimum operating temperature of $25^{\circ} \mathrm{C}$ above the highest acid dew point calculated so that there is no early saturation of the sleeves.

\section{References}

[1] Traversi, D., Degan, R., Marco, R., Gilli, G., Pignata, C. Villani, et al. 2009. "Mutagenic Properties of PM 2,5 Urban Pollution in the Northern Italy: The Nitro-compounds Contribution." Environment International 35: 905-910.

[2] Castro, A. H. S. 2013. "Air quality —Control Parameters and Effects on Human Health: a Brief Review." Holos 5 (1): 107-121.

[3] Barbosa, M. G., Silva, C. L. 2013. "Efficiency of a Bag Filter in the Treatment of Gases from a Solid Biomass Firing Boiler." Environmental Forum of the High Paulista 11 (9): 293-308.

[4] Dias, T., eds. 2008. Pulp and Paper-Protection and Economy with Filters. São Bernardo do Campo: Filter Media. 2008.

[5] Ceron, L. P., Einloft, S., Seferin, M. 2010. "Evaluation of the Drying Process of Non-woven Pet in the Manufacture of Insoles for Shoes, Exothermic Curves and Flexion
Index." Chemistry Textile 98 (1): 30-34.

[6] Cuiping, Y., Guijian, L., Haiyab, C. 2013. "Effect of Induced Airflow on the Surface Static Pressure of Pleated Fabric Filter Cartridges during Pulse Jet Cleaning." Powder Techno 249 (1): 424-430.

[7] Melo, F. A., Silva, J. N., Donzeles, S. M. L., Paula, A. L. T., eds. 2010. Evaluation of a furnace for direct heating of air using charcoal. SBICafé. 2010.

[8] Park, S. 2019. "Non-uniform Filtration Velocity of Process Gas Passing through a Long Bag Filter." Journal Of Hazardous Materials 365 (1): 440-447.

[9] Ceron, L. P. 2009. "Textiles for the Construction of Filtering Sleeves." Filter Medium 40:40-43.

[10] Ceron, L. P. 2012. "Particulate Filtration Technology using Nonwoven PTFE Membranes." Presented at the VIII International Symposium on Environmental Quality, Porto Alegre. Brazil.

[11] Clough, E. N. 2010. "Innovations in ePTFE fiber Technology: Capabilities, Applications, Opportunities." Man-Made Fiber Year Book 10: 50-53.

[12] Renner T. eds. 2001. Technical Manual of Fibers. Cachoeirinha. Brazil. 2001.

[13] Ceron, L. P. eds. 2019. Manual of Accessories for Filter Sleeves. Renner Têxtil: Porto Alegre. Brazil. 2019.

[14] Pacheco, T. A. 2005. "Chemical Aspects of Particulate Retention." Chemistry and Derivatives 6 (10): 40-51.

[15] Ceron, L. P. 2015. "Filtration of Biomass Burning in Boiler." Filter Media 74:16-23.

[16] Rocha, S. M. 2010. Study of the Influence of Velocity and Filtration Cycles on Cake Formation in Bag Filter Cleaning. UFU: Uberlândia. Brazil. 2010. 